\title{
Transfer of conservative and non-conservative radionuclides from the Sellafield Nuclear Fuel Reprocessing plant to the coastal waters of Ireland
}

\author{
C.A. McMahon ${ }^{1}$, M. Fegan ${ }^{1}$, J. Wong ${ }^{1}$, S.C. Long ${ }^{1}$, L. McKittrick ${ }^{1}$, \\ K. Thomas ${ }^{2}$, T.P. Ryan ${ }^{1}$ and B. Rafferty ${ }^{1}$ \\ ${ }^{1}$ Radiological Protection Institute of Ireland, 3 Clonskeagh Square, Dublin 14, Ireland \\ ${ }^{2}$ Food Standards Agency, Aviation House, 125 Kingsway, London WC2B 6NH, UK
}

\begin{abstract}
The Radiological Protection Institute of Ireland has monitored levels of anthropogenic radionuclides in the Irish marine environment for over 20 years. While the primary objective of the monitoring programme is to assess the exposure of the Irish population resulting from the presence of these radionuclides in the marine environment, the programme also aims to assess the geographical distribution and temporal variations of the radionuclides. The programme involves the routine sampling of and testing for radioactivity in fish, shellfish, seaweed, sediments and seawater. The data generated in the course of this programme, as well as in a separate study of changing plutonium isotopic ratios in Fucus vesiculosus from the west coast of Ireland, were used to estimate transport times from the Sellafield nuclear fuel reprocessing plant to various locations on the Irish coastline. For conservative radionuclides, transit times of 5-6 months to the NE coast of Ireland, 1-3 years to the south coast of Ireland and 3-8 years to the west coast were calculated. In contrast, for plutonium, the Sellafield signal was not observed on the west coast until the late 1980s/early 1990s.
\end{abstract}

\section{INTRODUCTION AND METHODOLOGY}

The most significant source of radioactive contamination in the Irish Sea is the discharge of low level liquid waste from BNFL's nuclear fuel reprocessing plant situated at Sellafield. Discharges began in 1952 and have varied over time due to changes in type/quantity of fuel reprocessed, and changes in waste treatment procedures (Figure 1). Discharges of most radionuclides peaked in the 1970s and declined to lower levels from the mid-1980s [1]. Technetium-99 discharges increased significantly from 1994 (peaking in 1995), due to processing of a backlog of liquid waste accumulated in anticipation of the commissioning of the Enhanced Actinide Removal Plant (EARP).

The initial dispersion of radionuclides from Sellafield is influenced by a number of factors including variations in the discharge rate, the chemical form of the radionuclides in the effluent, local hydrographic conditions and the distribution and composition of bottom sediments. The more soluble radionuclides such as ${ }^{99} \mathrm{Tc}$ and ${ }^{90} \mathrm{Sr}$ discharged from Sellafield are predominantly distributed according to the movements of the major tidal and residual currents (Figure 2). They are advected primarily to the north and west, leaving the Irish Sea via the North Channel, within approximately one year [2]. The less soluble particle-reactive radionuclides, such as plutonium and americium, are quickly removed from the water column by direct precipitation or by adsorption onto suspended particulate. The behaviour and distribution of these nuclides is closely linked to that of the finer grained seabed sediments and a combination of processes leads to subsequent dispersion of these sediment-bound radionuclides. 
Since 1977, the Radiological Protection Institute of Ireland (RPII), and its predecessor the NEB, have carried out a programme to monitor the levels of radioactive contamination in the Irish marine environment and to assess the resulting exposure of the Irish population. In addition, the programme aims to assess the distribution of contaminating radionuclides and to identify long term trends. The programme involves the routine sampling of and testing for radioactivity in fish, shellfish, seaweed, sediments and seawater. Details of this programme and the analytical techniques used are given elsewhere $[4,5]$.

The largest datasets from this monitoring programme were chosen and utilised to determine transport times from the source (Sellafield) to the Irish coast based on the observed trends in concentrations. In addition to temporal concentration patterns, radiocaesium and plutonium isotopic ratios in Fucus vesiculosus were examined and compared to the known ratios in Sellafield effluent and other sources. This allowed comparison of transit times obtained for conservative radionuclides with those obtained for non-conservative radionuclides.

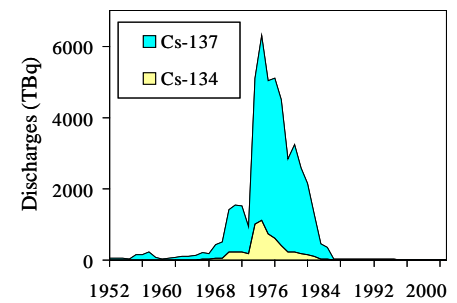

Year

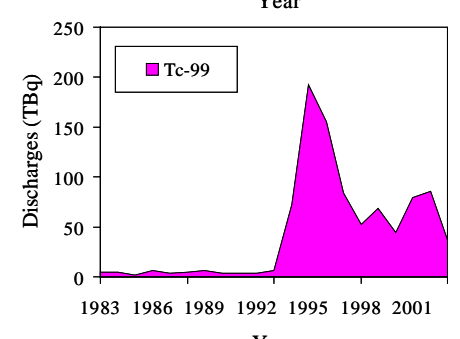

Year

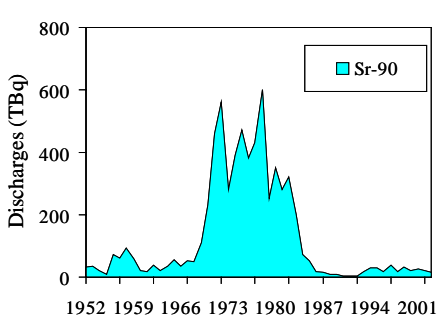

Year

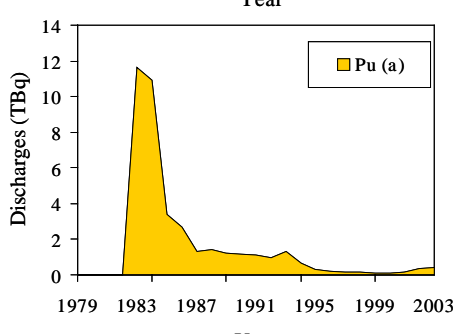

Year

Figure 1. Liquid discharges from Sellafield Nuclear Fuel Reprocessing Plant.

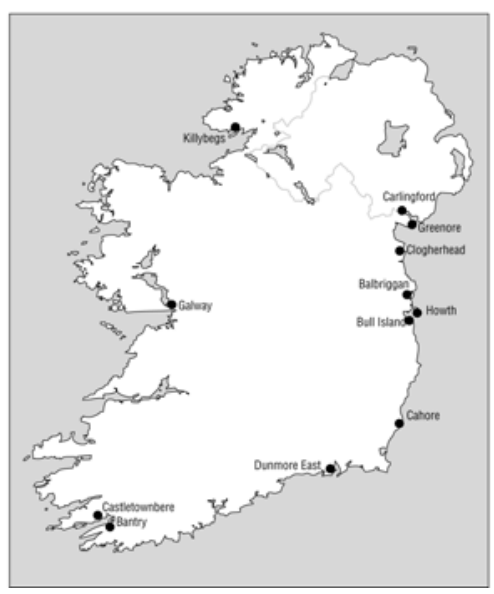

a)

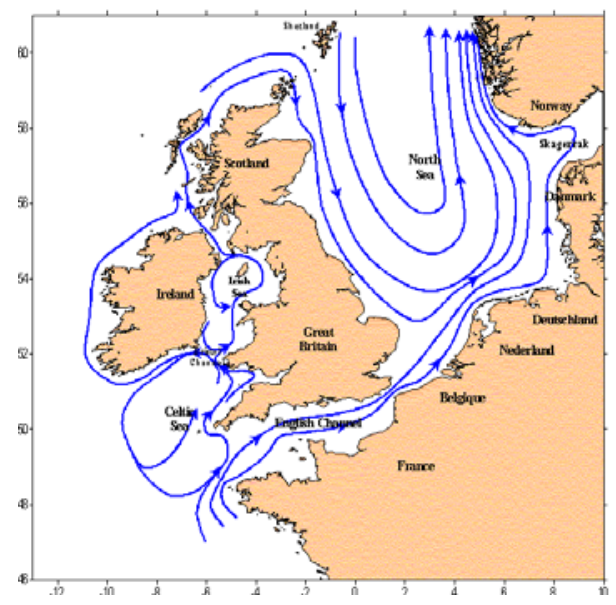

b)

Figure 2. Maps showing (a) sampling locations on the Irish coastline and (b) water circulation patterns in the surrounding waters. 


\section{RESULTS AND DISCUSSION}

The largest datasets available were for biota (mainly Fucus vesiculosus) concentrations. However, when using environmental concentrations to estimate transit times it is important that any possible effects from delayed uptake or biota age/accumulation times are considered. Thus, before transit times were calculated, datasets with matching seawater and biota concentrations from the same location were examined (e.g., Figure 3). It was clear that these factors had, at most, a minor effect on the calculated transit times.

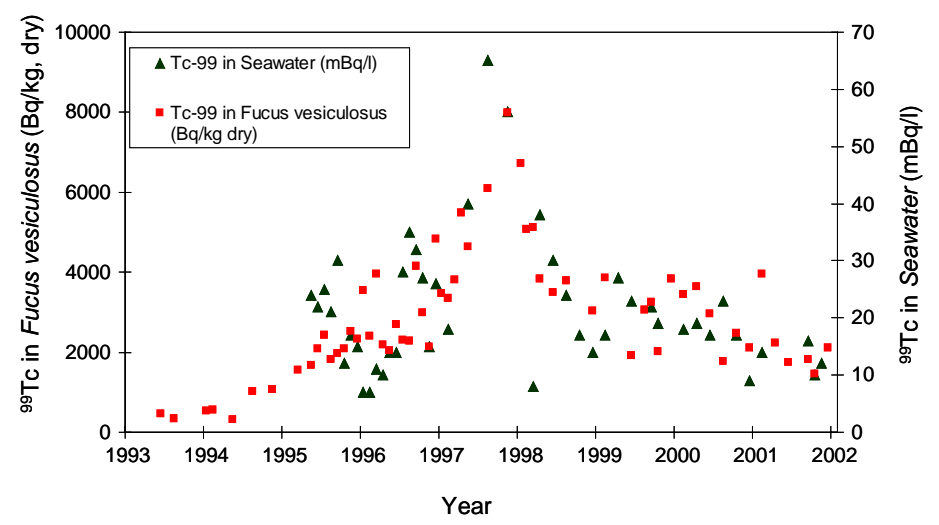

Figure 3. A comparison of ${ }^{99}$ Tc concentrations in Fucus vesiculosus and seawater from Balbriggan.

\subsection{North-East Coast of Ireland}

From the trends of ${ }^{137}$ Cs concentrations in Fucus vesiculosus (Figure 4) and also in cod concentrations (not shown) it was clear that changes in Sellafield discharges are reflected in concentrations on the NE coast of Ireland within two years.

In order to further refine the estimated transit time further, ${ }^{99} \mathrm{Tc}$ data for the transition period from pre-EARP to post-EARP operations at Sellafield was studied (when EARP came into operation a significant pulse of ${ }^{99}$ Tc was discharged). Using the ${ }^{99} \mathrm{Tc}$ in Fucus vesiculosus dataset, it can be seen that approximately five months after the first increased post-EARP discharges from Sellafield, the leading-edge of the pulse was beginning to impact on the environmental concentrations from the NE coast of Ireland. The observed concentrations peaked 18-24 months after the peak in discharges.

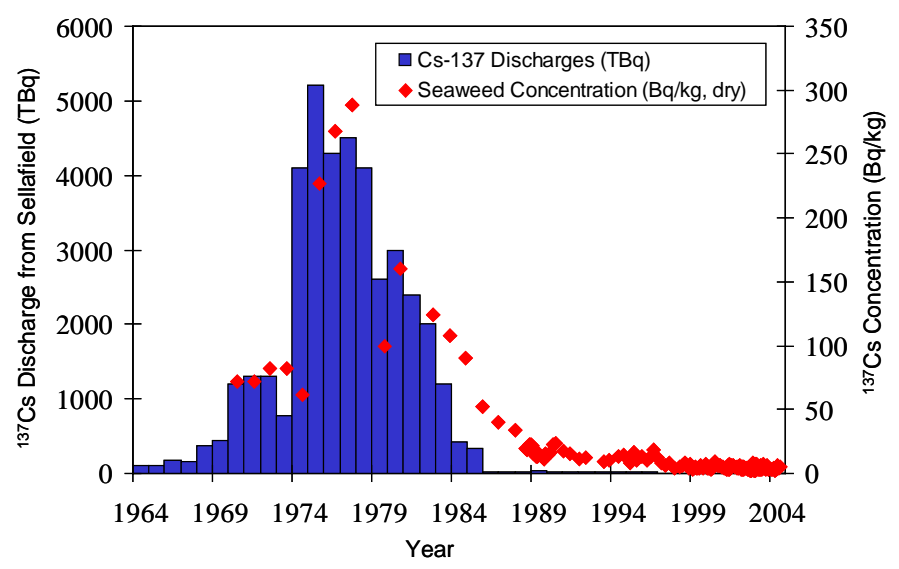

Figure 4. ${ }^{137}$ Cs Concentration trend in Fucus vesiculosus from Balbriggan compared to annual discharges from Sellafield. 
The 5-month time-lag for the leading edge of the pulse reflects the transit time of dissolved radionuclide species from Sellafield to Dublin and the 18-24 month time difference in discharge and concentration maxima reflects the mean availability time of ${ }^{99} \mathrm{Tc}$ in the western Irish Sea (Figure 5).
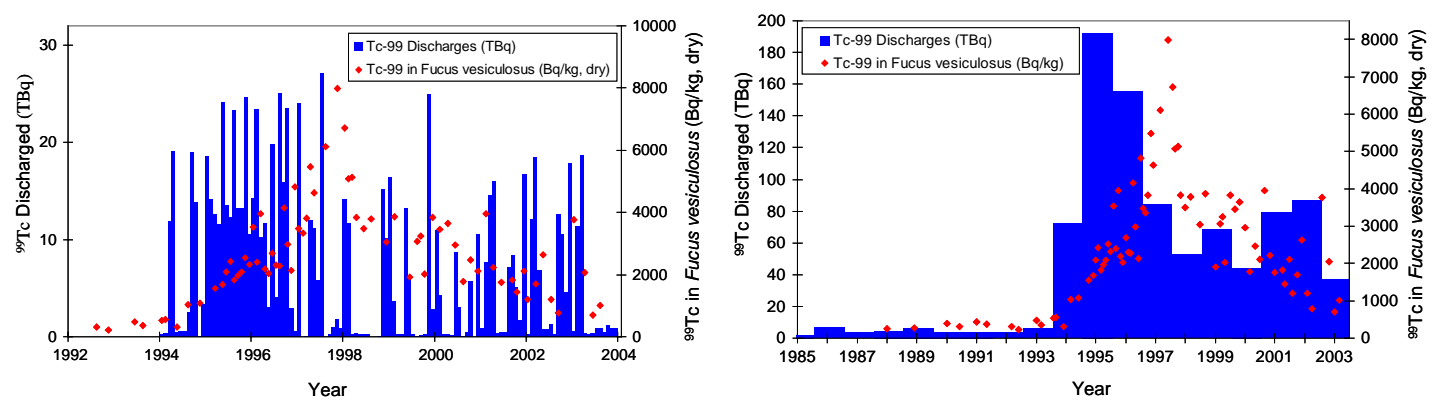

Figure 5. ${ }^{99}$ Tc concentrations in Fucus vesiculosus on the NE coast of Ireland compared to monthly and annual discharges from Sellafield.

\subsection{South Coast of Ireland}

Figure 6 shows the mean ${ }^{99}$ Tc concentrations in Fucus vesiculosus for a number of locations around the coast of Ireland in 2000 and 2001. As expected, the concentrations are highest on the NE coast (closest to the source- the Sellafield reprocessing plant). Concentrations decrease from Greenore to Cahore (south coast) to Galway (west coast) and to Killybegs (NW coast). This pattern can be attributed to the coastal current that carries water out from the Irish Sea in a southerly direction to the Celtic Sea and then sweeps around the coast in a clockwise direction. Using ${ }^{134} \mathrm{Cs} /{ }^{137} \mathrm{Cs}$ isotopic ratios measured in seaweed samples from the south coast prior to the Chernobyl accident, a transit time in the order of 1-3 years from Sellafield to the south coast of Ireland was estimated.

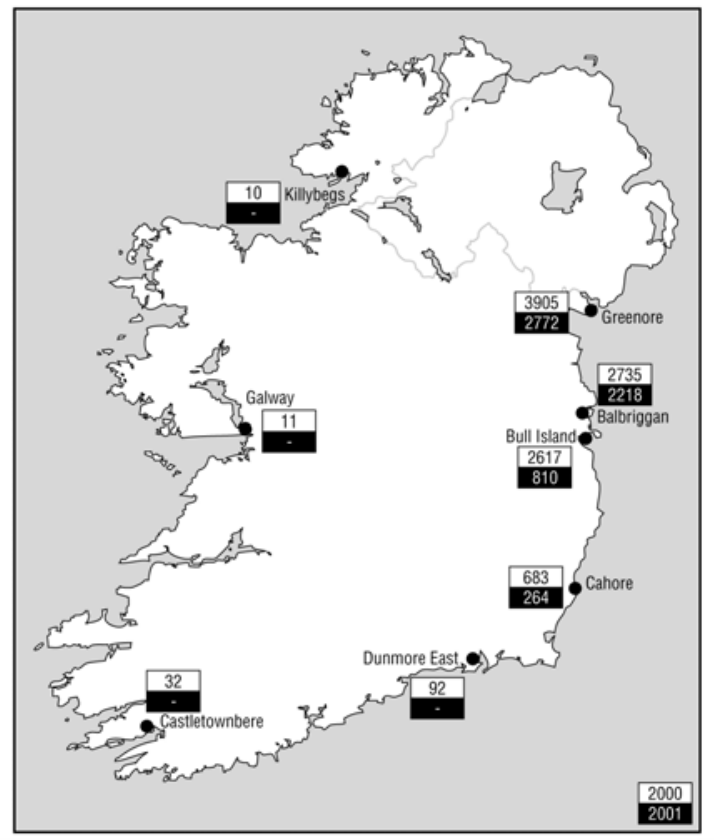

Figure 6. ${ }^{99}$ Tc concentrations in Fucus vesiculosus collected in 2000 and 2001. Concentrations are given in Bq/kg (dry). 


\subsection{West Coast of Ireland}

It has been observed that concentrations on the west coast tend to follow trends seen on the east coast of Ireland with a lag-time of less than 8 years (Figure 7). This provides an upper estimate of the transfer time, as the effect of availability times (as seen in ${ }^{99}$ Tc Fucus veisculosus concentrations on the NE coast) tend to increase apparent time-lags between discharge and concentration maxima. In addition to contributions from global fallout and Sellafield discharges, there was a small contribution of ${ }^{137} \mathrm{Cs}$ from Chernobyl in the late 1980s. Prior to the Chernobyl accident in May 1986, the level of ${ }^{134} \mathrm{Cs}$ in Fucus vesiculosus from the west coast of Ireland was well below the detection limit for the analytical method used. By assuming that the all the ${ }^{134} \mathrm{Cs}$ measured in samples in the affected years was of Chernobyl origin, the known ${ }^{137} \mathrm{Cs}:{ }^{134} \mathrm{Cs}$ ratio for Chernobyl fallout was used to subtract the Chernobyl contribution to ${ }^{137} \mathrm{Cs}$ concentrations in Fucus vesiculosus.

Furthermore, in November 1996, ${ }^{99}$ Tc activity concentrations in seawater on the west coast were below the limit of detection $(<0.14 \mathrm{mBq} / \mathrm{l})$, by September 1998 the seawater concentrations, though low, were above the limit of detection at three sites on the west coast [6]. Since the Sellafield ${ }^{99} \mathrm{Tc}$ discharges rose sharply in March 1994, this indicates that the transit time for ${ }^{99}$ Tc from Sellafield to the west coast of Ireland is in the order of 3-5 years. These estimated values for transit time are in good agreement with those estimated by Mitchell et al. [7] and Prandle [8] of 2-5 years.

In contrast, examination of the ${ }^{238} \mathrm{Pu} /{ }^{239,240} \mathrm{Pu}$ isotopic ratio in Fucus vesiculosus from Galway (Figure 7) shows that significant transfer of plutonium from the Sellafield to the west coast of Ireland did not occur until the late 1980s/early 1990s. Indeed, the ${ }^{238} \mathrm{Pu} /{ }^{239,240} \mathrm{Pu}$ isotopic ratio observed in Galway since the mid-1990s is clearly reflective of time-integrated Sellafield discharges (0.18) and not contemporary discharges (0.4-0.6) [2]. This signifies the growing importance of plutonium remobilised from Irish Sea sediments as a source to the west coast of Ireland.

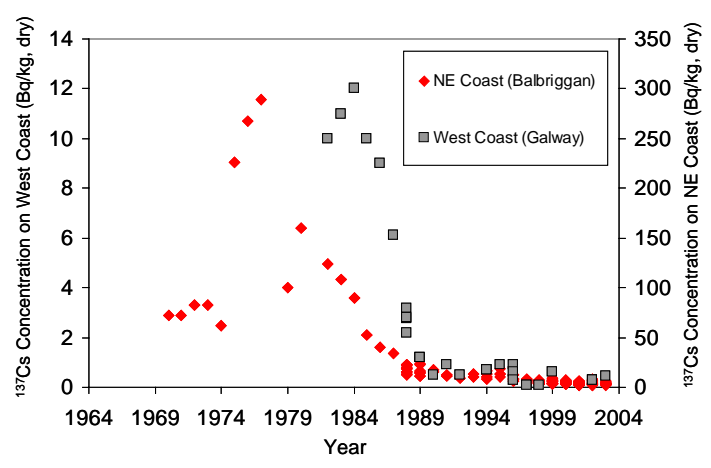

a)

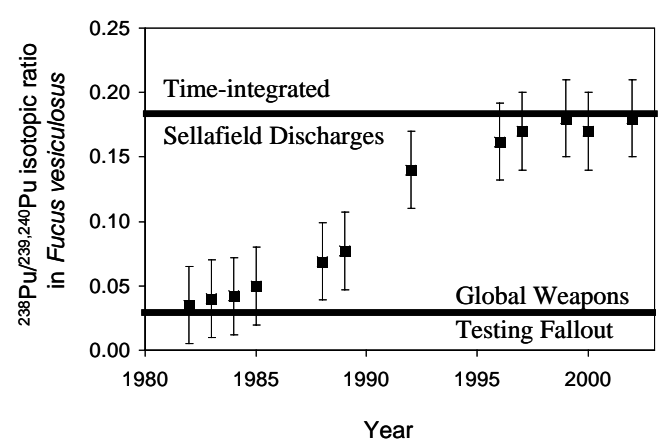

b)

Figure 7. a) ${ }^{137} \mathrm{Cs}$ Concentrations measured in Fucus vesiculosus from the NE and west Coasts of Ireland. b ${ }^{238} \mathrm{Pu} /{ }^{239,240} \mathrm{Pu}$ isotopic ratios measured in Fucus vesiculosus from the west coast of Ireland.

\section{CONCLUSIONS}

It has been possible to establish transit times from the Nuclear Fuel Reprocessing plant at Sellafield to various locations on the Irish coastline. This was achieved using a variety of methods, including examination of measurement of concentration trends and measurement of ${ }^{134} \mathrm{Cs} /{ }^{137} \mathrm{Cs}$ and ${ }^{238} \mathrm{Pu} /{ }^{239,240} \mathrm{Pu}$ ratios in environmental media, and by tracing the post-EARP pulse of ${ }^{99} \mathrm{Tc}$ in both seawater and seaweed.

For conservative radionuclides, transit times in the order of 5-6 months from Sellafield to the NE coast of Ireland, 1-3 years to the south coast of Ireland and 3-8 years to the west coast were calculated. In contrast, for plutonium, the Sellafield signal was not observed on the west coast until the 
late 1980s/early 1990s. Furthermore, the plutonium isotopic ratio was clearly indicative of time-integrated discharges and not contemporary discharges. The exact mechanisms for this transfer are not clear but it is thought that the plutonium was re-mobilised from Irish Sea sediments and then transferred in soluble form, or attached to colloidal material, to the west coast of Ireland. It is important to note that actual transfer times can vary greatly over short time periods with changes in, for example, water circulation patterns potentially having a significant effect on observed transit times for a particular period [9].

\section{Acknowledgments}

The authors are grateful to all he individuals involved in the generation of the monitoring data which was used in this study. This study was conducted as part of the EU FP5 Remotrans programme (Processes regulating remobilisation, bioavailability and translocation of radionuclides in marine sediments). The part-funding of this programme by the EU is gratefully acknowledged.

\section{References}

[1] Gray, J., Jones, S.R. and Smith, A.D. "Discharges to the environment from the Sellafield site 1951-1992", J. Radiol Prot. 15 (1995) 99-131.

[2] Environment Agency (UK), personal communication.

[3] Kershaw, P.J. and Baxter, A. "The transfer of reprocessing wastes from north-west Europe to the Arctic", Deep-Sea Res. II 42 (1995) 1413-1448.

[4] Long S., Pollard D., Hayden E., Smith V., Fegan M., Ryan T.P., Dowdall A. and Cunningham, J.D., Radioactivity monitoring of the Irish Marine Environment, 1996 and 1997. (Radiological Protection Institute of Ireland, Dublin, 1998).

[5] Ryan, T.P., McMahon, C.A., Dowdall, A., Fegan, M., Sequeira, S., Murray, M., McKittrick, L., Hayden, E., Wong, J., Colgan, P.A. Radioactivity monitoring of the Irish Marine Environment, 2000 and 2001. (Radiological Protection Institute of Ireland, Dublin, 2003).

[6] Smith, V., Fegan, M., Pollard, D., Long, S., Hayden, E. and Ryan, T.P. "Technetium-99 in the Irish marine environment", J. Environ. Radioactivity 56 (2001) 269-284.

[7] Mitchell, P.I., Collins, P.F., Sanchez-Cabeza, J.A., Vidal-Quadras, A. and Font, J.L. "Traces of Sellafield effluent off the west coast of Ireland", Il Jornados Sobre Fondo Radioactivo Ambiental, Barcelona, Spain, 12-13 May 1986, (Sociedad Nuclear Espanola, 1986).

[8] Prandle, D. "A modelling study of the mixing of ${ }^{137} \mathrm{Cs}$ in the seas of the European Continental Shelf", Phil. Trans. R. Soc.(Lond.) A310 (1984) 407-436.

[9] Kershaw, P.J., Heldal, H.E., Mork, K.A. and Rudjord, A.L. "Variability in the supply, distribution and transport of the transient tracer 99Tc in the NE Atlantic", J. Marine Systems 44 (2004) 55-81. 